\title{
Astrotheology: on exoplanets, Christian concerns and human hopes
}

Billions of stars populate the galaxies of our universe. Yet are there planets beyond our solar system as well? What may appear quite plausible had only been a hypothesis until about 20 years ago. Then, on October 5, two Swiss astronomers, Michel Mayor and Didier Queloz of the Geneva Observatory announced "the presence of a Jupiter-mass companion to the star 51 Pegasi" (Mayor and Queloz $1995,355)$, presumably circling its star in only four days.

Mayor's and Queloz's discovery of the first planet exterior to our solar system which was circling a sun-like star at first elicited skepticism. Discoveries like this one for too long had been swiftly disproven (Weintraub 2014, 43-50). Also, the features of the discovered planet did not match the expectations for planetary locations, drawn from the structure of our solar system. Yet the claim of Mayor and Queloz did hold. Today, we know: "The ... most remarkable result from the discovery of exoplanets is their variety" (Smith 2016, 8). More than 2000 of such "exoplanets" are confirmed. There will be likely millions more, as one can expect at least every tenth distant sun to be surrounded by a planet (Batalha 2014); other estimations talk about at least one planet on average per star (Wilkinson 2016,6 ). In this case, and if $25 \%$ of sun like stars have an earth sized planet in a habitable zone, there could be over 10 billion potentially habitable earths in our Galaxy (Wilkinson 2016, 7). There are at least about 300 billion stars in our galaxy alone, and billions of galaxies out there (Gribbin 2008, 28-291).

These exoplanets are just a bit hard to find, as they do not shine. How they can be found nevertheless, astronomer and theologian David Wilkinson explains in his article.

The search for exoplanets is driven by the interest in the "habitable" ones among them that is those which are in a suitable distance from their star which allows for liquid water, for instance. Could such a planet one day in the far future provide resources or even shelter for humankind? Will we find one day a habitable planet that is even inhabited? These kinds of imagination drive the public interest in the subject. Coupled with the natural curiosity of the scientists, they further the research agenda. In his contribution to this section, David Wilkinson warns against too hasty equating "earth like planets to habitable earth like planets and then to inhabited earth like planets and then to inhabited by intelligent beings earth like planets." (Wilkinson 2016, 8) We should keep Fermi's paradox in mind: If intelligent life really were abundant in the universe, "where is everybody?" (Webb 2002).

Interestingly, the imagination of alien intelligent life in the universe is not at all a new invention. Already the early Greek atomists expected "life out there" in an infinite cosmos (Crowe and Dowd 2013, 5). A revival of this idea of "many worlds" occurred when the Copernican revolution shattered Aristotelian and Ptolemaic geocentrism. Michael Crowe already described in an earlier issue of Zygon the history of the extraterrestrial life debate from antiquity until our days (Crowe 1997). A rough sketch of the developments can also be found in Michael Crowe's contribution to this section.

What is important to remember is that there were two principles supporting the idea of a plurality of inhabited worlds in the universe: 1) the Copernican principle, according to which "there is nothing

\footnotetext{
${ }^{1}$ When Gribbin speaks of "(at least three) hundred million stars in The Milky Way", this is simply a typo. Email from John Gribbin to the author on 27 January 2016.
} 
special about our region of space. This implied that other regions must share with Earth the presence of intelligent beings." (Crowe 2016, 2), and 2) the principle of plenitude: the more life in the universe the greater the glory of God, it assumed, as God "would not waste the efforts involved in producing the universe without placing within it widespread ETI [Extraterrestrial Intelligence]" (Crowe, 3). So there had to be most likely life everywhere, as "the heavens declare the glory of God." (Psalm 19:1)

It hence may not surprise the reader that even Immanuel Kant was an adherent of the idea of a plurality of inhabited worlds, and remained so even in his critical phase (Szendy 2013, 43-79; Losch 2015). David Dunér provides an in-depth study of the thought of his contemporary speculative counterpart, Emanuel Swedenborg, who had a scientific past, and tried to reconcile the science of his time - including the belief in extraterrestrials - with spirituality and theology. Swedenborg also claimed to have talked to the extraterrestrials in person, by the means of his spiritual journeys, a stance Kant deliberately tried to distance himself from (E.g. Kant 1766). In any case, Swedenborg's attitude allows for a glimpse into $18^{\text {th }}$ century belief in extraterrestrial life and gives us a taste of that century's thought.

The degree to which belief in ETI had permeated the public in the first half of the nineteenth century is indicated by an event that occurred in 1835, called today "The Great Moon Hoax". A series of newspaper articles suggested that prominent astronomer Sir John Herschel had telescopically detected intelligent beings on the Moon. Although nearly everyone believed the reports (Crowe $2016,8)$, it was only fiction. The popularity of the discussion testifies to how widespread the belief in ET life was. Likewise, Percival Lowell's "observation" of canals on Mars sustained the belief (Smith 2016, 3).

The expectations of ETI changed in the course of the $19^{\text {th }}$ century, and mostly due to the findings of one person, William Whewell. According to Michael Crowe's contribution to this section prominent scientists like Sir William Herschel before Whewell did not hesitate to speculate life even on the Sun (Crowe 2016, 4). Whewell demurred. His application of the inverse square law and his knowledge of geology lead him to believe that large areas of the sky have to be devoid of population. His motivation may have been religious ("The earth... cannot, in the eyes of any one who accepts this Christian faith, be regarded as being on a level with any other domiciles." (Whewell 1853, 44)), yet by questioning the principle of plenitude and the argument from design, he almost paved the way for Darwinian findings, one could maybe add to Michael Crowe's most elaborate and thoughtful reconstruction of Whewell's thought (Whewell 1853, 210-47).

One of the books popularizing the idea of a plurality of habitable worlds was William Derham's "Astro-Theology" (Derham 1715), which saw many editions worldwide. His "Astro-Theology" was one application of the more general idea of a physico-theology, meaning that "the wonderful and astonishing order and efficiency we can see in nature, the countless life forms we can find on earth, show that there must be an omnipotent and infinitely wise Creator." (Dunér 2016, 5) Derham himself also authored a more general "Physico-Theology" (Derham 1713), yet the objections of Hume and Kant make such a belief today superfluous, although it is true as Kant noted, that such a creed indeed "enlivens the study of nature" (Kant 1998, 579 = A623; B651).

When Ted Peters called for an establishment of the field of "astrotheology" (Peters 2014), he was certainly less thinking of these ancient attempts, but more coining the word analogously to the emerging field of astrobiology. There had been a previous field called exobiology - the study of extraterrestrial life forms - but due to the lack of findings, one enlarged the field to encompass the 
only life we know of until today. Likewise, most theological researchers followed in calling their theological interpretations of the astrobiological expectations "Astrotheology" instead of "Exotheology".

For the theologian, the sheer possibility of intelligent life beyond our planet carries some implications, which need a good deal of theological reflection. David Wilkinson picks up on these in the second part of his essay, clarifying that although the recent discoveries emphasize the extravagance of a Creator God, "Christian theology will resist any attempt to resurrect any design argument on the basis of exoplanet discoveries" (Wilkinson 2016, 11). Nevertheless, acknowledging the great diversity of Creation "means that it is to be respected and cared for as a gift." (Wilkinson 2016, 10)

Ted Peters in his article explores the field of "Astrochristology", thereby listening to the choir of theological voices emphasizing the compatibility of modern religious beliefs and astrobiological expectations. Against Thomas Paine's old (and often repeated) assumption that "to believe God created a plurality of worlds ... renders the Christian system of faith at once little and ridiculous, and scatters it in the mind like feathers in the air" (Paine 1794, 84), the contributors to this kind of concert make a compatibility of Christianity with the idea of a plurality of worlds appear sound. Two crucial issues have to be dealt with: if there is intelligent extraterrestrial life on exoplanets, should Christians expect multiple incarnations or simply one on Earth? And, more fundamentally, why is there an incarnation in the first place? Is it simply a sign of divine self-communication or is it needed to fix a broken creation? These questions entail considerations of anthropocentrism and geocentrism. Was it relevant that Christ had become human? Did he also become an extraterrestrial fellow being? Peters claims, following biblical resources, a universality of the Christ event, without denying the possibility of other divine self-revelation "that could take place anywhere at any time" (Peters 2016, 17).

Will astrobiology and astrotheology result in the decentering of humanity in cosmic dimensions? (Cf. (Drees 2000,69) Maybe they could result in changing our life-value narratives, as Lucas Mix argues. Although he follows Hume in his traditional "is" and "ought" divide, he also believes that "the empirical ground affects our morality, even though it does not fully determine it" (Mix 2016, 1). Mix employs the metaphor of seeds and soil (the narratives that grow out of fundamental ethical convictions) to develop his thoughts. He describes two dominant, yet divergent tropes, the Pale blue dot-trope - who are we, what is Earth in the vastness of the universe? - and the Anthropocene trope: we are living in the age of humans who change the face of our planet, which sets us apart from other life. The two tropes have both been used to support holistic life-value narratives over hierarchical narratives "with Christian theology set up as the opposition" (Mix 2016, 5). Nevertheless, scriptural witness demonstrates a plurality of life-value narratives. Mix' conclusion is: "The Hierarchical and Holistic Narratives provide a way to think about the relative value of biological and human life within the cosmos, and provide tools for analyzing both seeds and soil as we cultivate new ethical paradigms." (Mix 2016, 10)

In his former survey article (Peters 2014, 447), Ted Peters already mentioned the different branches of Astroethics which are needed to be discussed, be it (1) Astroethics for microbiological life in our solar ghetto, like (a) Planetary protection, (b) Space debris, (c) Satellite surveillance, (d) Scientific privilege vs. space profit and (e) Weaponization of space or (2) Astroethics for intelligent life in the larger Milky Way metropolis. What was in my view missing from the list is the more fundamental 
level, Mix touches upon. What is Life? Which value does human life possess in cosmic dimensions? Who can say so? "Where does the ought come from?", as Margaret Race (SETI Institute) put it during an astrotheology-workshop held at the CTNS Berkeley in June 2015. The papers presented at the workshop are most likely published in the journal Theology \& Science. There have been further events in the framework of the International Society for Science and Religion's (ISSR's) meetings at the AAR in 2013, resulting in a compilation on astrotheology soon to be published (Peters et al. forthcoming).

Also the European Society for the Study of Science and Theology (ESSSAT) recently took up questions touching astrobiological questions in their biannual conferences, asking "Are we special?" in 2016, and "What is Life?" already in 2012 (Evers et al. 2015). Besides, the field of astrobiology itself is open for contributions from the humanities and from theology. The Center for Space and Habitability (CSH) in Bern, Switzerland, hired a theologian and started a project with theology: "Life beyond our planet?" (www.lifebeyondourplanet.unibe.ch) Mark the question mark at the end of the project's title, which an internet address unfortunately cannot contain. The first fruit of this project had been another conference on "What is Life?", resulting in a book involving science, philosophy and theology (Losch forthcoming). Also a volume in Cambridge University Press' astrobiology series showed the openness and need of the field for ethical and theological considerations (Bertka 2009). Oxford University Press is not idle either, having important titles like David Catling's "Very Short Introduction" into astrobiology (Catling 2013) and David Wilkinson's Science, Religion and the Search for Extraterrestrial Intelligence in their program (Wilkinson 2013). With astrobiology taking more realistic ground with the discoveries of exoplanets, there are more and more books in the making reflecting on the potential impact of extraterrestrial findings (E.g. Vakoch 2013, Impey, Spitz, and Stoeger 2013, Hart 2013; Dunér et al. 2013.). Even the Royal Society dedicated one of its transactions to such a discussion (Dominik and Zarnecki 2011). The mentioned project at Bern is currently trying to map the many contributions and establishing an Online Library on topic, to be published on its website.

The European "Nordic Astrobiology Network" dedicated one of its summer schools and several conferences to the contribution of the humanities, resulting in a special issue of the International Journal of Astrobiology (titled "The history and philosophy of the origin of life", guest editors David Dunér, Christophe Malaterre and Wolf Geppert, forthcoming). On the other side of the Atlantic, NASA is of course a highly important player in our regards, and from early on invited researchers from the humanities and theologians to contribute (Berendzen 1973). Also today, NASA's astrobiology program conjointly with the Templeton Foundation sponsors research fellowships at the Center for Theological Inquiry (CTI) in Princeton, opening an "Inquiry on the Societal Implications of Astrobiology". NASA's many years chief historian, Steven J. Dick, who authored several historical books on the topic (Dick 1982, 1996), was one of the pioneers in the fields, others being Karl S. Guthke at Harvard (Guthke 1990, English translation of Guthke 1983) and Michael Crowe at Notre Dame (his classic is of course Crowe 1999. A more recent source book is Crowe 2008). Steven J. Dick and Michael Crowe exchanged their materials and worked together. A student of Crowe is Michael Dowd (Notre Dame as well), who recently coedited with Douglas Vakoch from the SETI institute an extensive discussion of the famous equation by SETI pioneer Frank Drake (Vakoch and Dowd 2015). Finally, the Vatican Observatory has to be mentioned, which drew some media attention with questions like "Would you baptize an Extraterrestrial"? (Consolmagno 2014) 
This raises the question: What do religious people think about ET Life? Here, the "Peters ETI Religious Crisis Survey" has to be mentioned, which came to the conclusion that "religious persons, for the most part, do not fear contact. Forecasts regarding imminent collapse of earth's religious belief systems were found to be more prevalent among non-religious respondents than among religious respondents" (Peters and Froehling 2008). Although the data sample Peters rests his findings on could be bigger, the evidence for believers being less troubled with the possibility of ET life seems strong.

Another effort to map the different religions' stances on topic is David A. Weintraub's "Religions and Extraterrestrial Life", which makes use of religious literature on topic. To grant the plurality of Earth's religions some ground, Howard Smith's article, the last one of our section in this issue of Zygon will include, therefore, also a Jewish perspective on astrotheology. According to traditional rabbinic interpretation, ETI is even included in the Biblical narrative. More important, Smith's stance is also a more skeptical (Smith himself would say "more realistic") approach to the topic, employing the "misanthropic principle". Relativity constraints on the speed of light and the fact of the universe's continuous expansion lead him to conclude: "We are probably alone, at least for all practical purposes" (Smith 2016, 2) This would present of course a dilemma for religious believers, "who have spent centuries showing that Divine potency or grace should naturally imply many extraterrestrial civilizations, but who now must justify the need for the cast, excess cosmos beyond human reach." (Smith 2016, 19) We should, however, rejoice in our good fortune. "Atheists and religious people alike can also identify in it an expression of pride in humanity" (Smith 2016, 18). With it comes an ethical responsibility we have already spoken of.

Astrotheology is a rising field, yet for now it is not clear, if it - like Astrobiology - has any other subject than Earthly life and religion. Many would say, at least, that due to the vastness of the universe with all its planets, it is very probable to have a broader basis. Yet this is still an issue of assumptions, hopes and beliefs, maybe another reason besides the necessary ethical considerations, why philosophy and theology are important dialog partners for science here. In this context, and especially regarding the mythical hope of alien salvation that drives the SETI institute (Peters 2009, 19), theology should not forget its critical, prophetic function (Jackelén 2008) and remain sober and realistic. So the astrotheology of today, different then in $18^{\text {th }}$ century past, should include the possibility of a 0 result. The problem is, however, that in cosmic dimensions it is incredibly difficult to verify something not being there. And then, maybe it is also a little too tempting easy for earthly religion to stay anthropo- and geocentric, so what sounds sober could also turn out to be biased as well.

\section{References}

Batalha, Natalie M. 2014. “Exploring Exoplanet Populations with NASA's Kepler Mission." Proc. Natl. Acad. Sci. U.S.A. 111 (35): 12647-54. doi:10.1073/pnas.1304196111.

Berendzen, Richard, ed. 1973. Life beyond Earth \& the Mind of Man. Washington, D.C. NASA.

Bertka, Constance M. 2009. Exploring the origin, extent, and future of life: Philosophical, ethical, and theological perspectives. Cambridge astrobiology 4. Cambridge, UK, New York: Cambridge University Press.

Catling, David. 2013. Astrobiology: A very short introduction. Very short introduction 370. Oxford, United Kingdom: Oxford University Press. 
Consolmagno, Guy. 2014. Would you baptize an extraterrestrial? ... and other strange questions from the inbox at the Vatican Observatory. First Edition. New York: Image.

Crowe, Michael J. 2016. "William Whewell, the Plurality of Worlds, and the modern Solar System." Zygon (this issue).

- - . 1997. “A History of the Extraterrestrial Life Debate." Zygon 32 (2): 147-62. doi:10.1111/05912385.801997079 .

- - . 1999. The extraterrestrial life debate, 1750-1900. Mineola, N.Y. Dover Publications.

- - . 2008. The extraterrestrial life debate, antiquity to 1915: A source book. Notre Dame, Ind. University of Notre Dame.

Crowe, Michael J., and Matthew F. Dowd. 2013. "The Extraterrestrial Life Debate from Antiquity to 1900." In Astrobiology, history, and society: Life beyond Earth and the impact of discovery, edited by Douglas A. Vakoch, 4-56. Advances in astrobiology and biogeophysics. Berlin, New York: Springer.

Derham, William. 1715. Astro-Theology: Or a Demonstration of the Being and Attributes of God, from a Survey of the Heavens. Illustrated with Copper-Plates. by W. Derham,. London: printed for W. Innys.

Derham, William. 1713. Physico-Theology, Or, a Demonstration of the Being and Attributes of God from His Works of Creation: Being the Substance of XVI Sermons Preached in St. Mary Le Bow-Church, London, at the Hon'ble Mr. Boyle's Lectures in the Years 1711 and 1712 : with Large Notes and Many Curious Observations Never Before Published. London: printed for W. Innys.

Dick, Steven J. 1982. Plurality of worlds: The origins of the extraterrestrial life debate from Democritus to Kant. 1. publ. Cambridge u.a. Cambridge Univ. Pr.

- - . 1996. The biological universe: The twentieth-century extraterrestrial life debate and the limits of science. 1. publ. Cambridge u.a. Cambridge Univ. Press.

Dominik, Martin, and John C. Zarnecki, eds. 2011. The detection of extra-terrestrial life and the consequences for science and society $369 \mathrm{nr}$. 1936, pp. 497-699. London: The Royal Society. http://rsta.royalsocietypublishing.org/content/vol369/issue1936/.

Drees, Willem B. 2000. “Betlehem: Center of the Universe?” In God for the $21^{\text {st }}$ century, edited by Russell Stannard, 67-70. Radnor, PA: Templeton Foundation Press.

Dunér, David. 2016. "Swedenborg and the Plurality of Worlds: Astrotheology in the Eighteenth Century." Zygon (this issue).

Dunér, David, Joel Parthemore, Erik Persson, and Gustav Holmberg. 2013. The History and Philosophy of Astrobiology: Perspectives on Extraterrestrial Life and the Human Mind. Newcastle upon Tyne: Cambridge Scholars Publishing.

Evers, Dirk, Michael Fuller, Antje Jackelén, and Knut-Willy Sæther, eds. 2015. Issues in Science and Theology: What Is Life? Issues in Science and Religion. Cham, s.I. Springer International Publishing. http://dx.doi.org/10.1007/978-3-319-17407-5.

Gribbin, John. 2008. Galaxies: A Very Short Introduction. Very short introductions. New York: Oxford University Press.

Guthke, Karl S. 1983. Der Mythos der Neuzeit. Bern \& München: Francke.

Guthke, Karl S. 1990. The Last Frontier: Imagining Other Worlds, from the Copernican Revolution to Modern Science Fiction. With the assistance of H. Atkins. Ithaca, NY: Cornell Univ. Press.

Hart, John. 2013. Cosmic commons: Spirit, science, and space. Eugene, Oregon: Cascade Books. 
Impey, Chris, Anna H. Spitz, and William R. Stoeger. 2013. Encountering life in the universe: Ethical foundations and social implications of astrobiology. Tucson: The University of Arizona Press.

Jackelén, Antje. 2008. "What Theology Can Do for Science." Theology and Science 6 (3): 287-303. doi:10.1080/14746700802206941.

Kant, Immanuel. 1766. Träume eines Geistersehers. Riga, Mietau: [s.n.].

- - . 1998. Critique of Pure Reason: transl. and ed. By Paul Guyer and Allen W. Wood. Cambridge: Cambridge University Press.

Losch, Andreas, ed. forthcoming. What is Life? On Earth and beyond. Cambridge: Cambridge University Press.

- - . 2015. "Kants Wette: Von Kants starkem Glauben an außerirdisches Leben, der Geschichte dieser Fragestellung und ihrer Herausforderung für die Theologie heute." Theologische Zeitschrift (1): 23-47.

Mayor, Michel, and Didier Queloz. 1995. “A Jupiter-Mass companion to a solar-type.” Nature 1995 (378): 35559.

Mix, Lucas. 2016. “Life-Value Narratives and the Impact of Astrobiology on Christian Ethics.” Zygon (this issue).

Paine, Thomas. 1794. The Age of Reason: Being an Investigation of True and of Fabulous Theology and Author of the Works Entitled, 'Common Sense, and Rights of Man.'. Paris.

Peters, Ted. 2016. “Astrobiology and Astrochristology." Zygon (this issue).

- - . 2009. "Astrotheology and the ETI Myth." Theology and Science 7 (1): 3-29. doi:10.1080/14746700802617097.

- - . 2014. “ASTROTHEOLOGY: A CONSTRUCTIVE PROPOSAL.” Zygon ${ }^{\circledR} 49$ (2): 443-57. doi:10.1111/zygo.12094.

Peters, Ted, and Julie Froehling. 2008. "The Peters ETI Religious Crisis Survey." http://www.counterbalance.net/etsurv/index-frame.html.

Peters, Ted, Martinez Hewlett, Joshua Moritz, and Robert J. Russell, eds. forthcoming. Astrotheology: Science \& Theology Meet Extraterrestrial Life.

Smith, Howard A. 2016. "Alone in the Universe." Zygon (this issue).

Szendy, Peter. 2013. Kant in the land of extraterrestrials: Cosmopolitical philosofictions. First edition. New York: Fordham University Press.

Vakoch, Douglas A., ed. 2013. Astrobiology, history, and society: Life beyond Earth and the impact of discovery. Advances in astrobiology and biogeophysics. Berlin, New York: Springer.

Vakoch, Douglas A., and Matthew F. Dowd, eds. 2015. The Drake Equation: Estimating the Prevalence of Extraterrestrial Life Through the Ages. Cambridge astrobiology 8. Cambridge: Cambridge Univ. Press.

Webb, Stephen. 2002. Where Is Everybody? Fifty Solutions to the Fermi Paradox and the Problem of Extraterrestrial Life. New York: Copernicus Books.

Weintraub, David A. 2014. Religions and extraterrestrial life: How will we deal with it? Springer-Praxis books in popular astronomy. Cham: Springer.

Whewell, William. 1853. Of the plurality of worlds: an essay: Also a dialogue on the same subject. London: John W. Parker and Son.

Wilkinson, David. 2016. "Searching for another Earth: The Recent History of the Discovery of Exoplanets." Zygon (this issue).

- - - 2013. Science, religion, and the search for extraterrestrial intelligence. First edition. Oxford, U.K. Oxford University Press. 